\title{
THE FUTURE OF SAFETY SCIENCE
}

\author{
Paul Swuste ${ }^{1}$, Jop Groeneweg ${ }^{2}$ Coen van Guljik ${ }^{3}$, Walter Zwaard ${ }^{4}$, Saul Lemkowitz ${ }^{5}$, \\ Yvette Oostendorp 6
}

Manuscript Safety Science, November $3^{\text {rd }} 2019$, word count: 10306

\begin{abstract}
${ }^{1}$ Safety Science Group, Delft University of Technology, the Netherlands
2Unit of Cognitive Psychology Leiden University and TNO the Netherlands

3University of Huddersfield, West Yorkshire, UK

${ }^{4}$ Writer and independent consultant, Delft, the Netherlands

${ }^{5}$ Product \& Process Engineering, Delft University of Technology, the Netherlands

${ }^{6}$ Council for the Environment and Infrastructure, The Hague, the Netherlands
\end{abstract}

\section{ABSTRACT}

\section{INTRODUCTION}

1.1 Time travel

1.2 Innovate, risk concept and prevention

1.3 Science and practice

2 THE FURTURE OF SAFETY SCIENCE

2.1 Questions for the future

2.2 Old problems, new jacket

2.2 Challenges, complex production and complicated laws and regulations

2.3 Examples of high-tech-high-hazard sector, language, safety-aversion, and design

2.4 Knowledge, linear models, quantification, tracing scenario developments

2.5 Impact of non-linear models, safety theory and practice

2.6 Education

2.7 Two non-western countries, Pakistan and China

3 DISCUSSION AND CONCLUSIONS

REFERENCES

\section{ABSTRACT}

Following a quote from Heinrich, referring to the past is to look at the future, this contribution starts with a time traveller from the 19th century, who is very surprised, sometimes astonished, and now and then familiar with present day, and future developments in safety. The first part shows developments and achievements in our understanding of accident processes and safety improvements during the last 150 years. The second part explores some challenges and developments of the coming decades with the rise of new technologies, in both developed and developing countries.

Ever since safety started to be investigated in a consistent manner, around 150 years ago, there has been a tremendous improvement, both in our understanding of accident processes, and in harm and damage caused by these occupational and major accidents. Major improvements in safety theories, and models were made after World War II, with the late 1970s till the late 1990s as the 'golden years'. 
But still these major accidents occur and they will keep prompting future scientific developments in safety, as they have done in the past. Reducing the frequency of major accidents remains challenging. Design, as starting point for safety has its limits due to the complexity of processes and the inability to foresee all safety related conflicts. The modern emphasis to assure the capacity to handle unforeseen events, such as resilience promises to deliver, will become even more important in the future. Inherent safe design on the other hand make a sensible approach when designing production processes for emerging and future technologies, like nano- and biotechnology. Also, it will remain difficult for small and medium sized enterprises to adhere to complicated laws and regulations. In addition, an increased participation of interest groups makes future safety decision-making even more challenging than it already is today. Yet we foresee that there may be grounds for change in which safety rules, laws and regulations are set aside, the bureaucratic approach towards safety is stopped and the focus is on dynamic accident processes detection. Today, methods are developed to automatically assess time-dependant advancement of accident scenarios and barrier degradation. This direction will contribute substantially to a future level of safety in different industrial sectors and might alleviate the emphasis on bureaucracy.

There are elements of safety are challenging today and will probably get worse in the future. Climate change is an existential risk, creating possibly a future societal drift. Closer to home is a further digitalisation of safety critical systems and forthcoming energy transitions, leading to new failure modes. Another threat is the risk of language ignorance. With a forthcoming steady migration of worker, either low educated or only partly speaking the local language, there will be a problem understanding written safety information. Some challenges are less clear today but will become prevalent in the future. Will safety theories and methods add value to the health care sector? Can we close the existing gap between 'safety in practice' and 'safety as science'? Is it possible in the future to integrate occupational, high-tech-high-hazard and environmental safety? And finally, do we need dynamic safety models to investigate all our safety conflicts? Special attention is payed to present and future developments in safety in two non-Western countries; Pakistan and China as exponents of non-western influences on the safety domain.

But despite all that, the main threat is the domain of safety science itself. Being a multi-disciplinary domain and lacking a unifying theory makes the domain a relatively unattractive research domain for universities that tend to thrive on mono-disciplinary environments where there is less disagreement on basic priciples. 


\section{INTRODUCTION}

This work is an essay on the future of safety science. It sets out with some highlights of the changes and developments of the last 150 years till today. The succinct journey covers where safety came from, what the role of innovations and science versus practice. From this history overview we extrapolate our expectations of future developments.

\subsection{Time travel}

'Rarely is a problem unique. You can usually find something in past experience to offer some clues to the future'. The quote is from Heinrich and his co-author Lateiner, in a book published seven years after Heinrich's death (Lateiner and Heinrich, 1969). To honour this quote this contribution starts with a journey of a time traveller coming from the second part of the $19^{\text {th }}$ century.

Safety promotion exhibitions began in European countries and in the United States in the late $19^{\text {th }}$ century and the beginning of the $20^{\text {th }}$ century (Swuste et.al., 2010). Visitors would then have gazed at technical devices such as protective coverings of moving parts, like cogwheels, and fans for extracting hazardous fumes, to modern technical facilities that could have made work safer, but were nevertheless not applied in practice. If a visitor then had been able travel to the present with a time travel machine, he, or she would have experienced a remarkable change in the approach to safety. Perhaps our time traveller had read 'Hard Times', the novel of Charles Dickens that dramatically described $19^{\text {th }}$-century British industry full of worker exploitation, insecurity and danger (Dickens, 1854). Fortunately, nowadays, at least in the Western world, these dreadful working conditions described by Dickens hardly exist anymore. Applications of safety facilities that were exhibited in those early days have since become commonplace.

Not surprisingly, the number of accidents in the industry has since fallen dramatically. In the United States, for example, around the end of the $19^{\text {th }}$-century hundreds of large explosions took place in factories every year. American industry killed thousands every year, and tens of thousands were seriously injured (see e.g. Klein, 2009). And outside America's factories the situation was not much better. In 1910, more than 3,000 railway workers were killed and almost 100,000 were seriously injured. Much has improved and we don't have to go back a century to come to a similar conclusion. When comparing the 1970s with today's statistics a spectacular decrease in occupational mortality, in plane crashes, in traffic accidents is observed.

The time traveller would be surprised that today a field has emerged, safety science, with inspiring models and fruitful theories (Zwaard, 2007; Gulijk et al., 2009; Swuste et al., 2010, 2014, 2016a, 2019a-c; Oostendorp et al., 2016). There has been a shift in thinking about causes of accidents. A century ago, the worker was to blame for an accident; he was 'accident prone'. At that time, the 
employee was a cheap consumable, and was trashed just as easily as a defective wheel. It wasn't uncommon that factory doors were locked during working hours to prevent employees from leaving the workplace. Many workers died in fires but the risk of being locked up during a fire was never contemplated. Investigations of disasters then usually focused entirely on the role of the employee, only occasionally on the failing technology and almost never on virtually blame-free managers. The concept of 'just culture' was unknown in those days. Even in evidently unsafe situations, such as working with steam boilers without pressure relief, more than a century passed before adequate safety measures were introduced. Today, causes of accidents are viewed more comprehensively. Organizational, people-oriented and technical factors are now seen as essential elements in accident processes. That contemporary management of organizations feels co-responsibility for occurrence of accidents is relatively new. It urges management to take measures early in the product life cycle, in early design, and in pre-production stages, even though such measures in the short run sometimes come at the expense of turnover, or profit (see for instance Chemical Industries Association, 2008; Rademaeker et.al., 2014).

\subsection{Innovate, risk concept and prevention}

The innovative steps that made safety, and, more recently, responsibility and sustainability would become a core value of companies would be alien, even unthinkable, in the eyes of our time traveller. He or she would be astonished to see that in some national and international leading companies, health and safety of workers and process safety are as important as quality of production, financial successes, productivity, and cost reductions. Through decades of optimisation and implementation managers today encourage reporting of (near) accidents and demand in-depth analyses of all serious incidents to uncover the problems at system level and to be able to take measures. The way in which government views safety issues is also new to our time traveller. Government nowadays is more aware of its role in relation to safety and stimulates initiatives and tightens regulations (Covelle and Mumpower, 1988). Our time traveller would be surprise at the widespread safety perception by everybody involved in, and outside industry. Even if modern 'safety monitors' show that not all inventions are introduced in all companies, and management rhetoric's that 'safety is number one in our company' is not always followed by appropriate actions and initiatives, the situation is much improved. That does not mean there are no concerns for our time-traveller: today's media coverage of dramatic events, such as plane crashes, are easily perceived as indicators for that we might be living in unsafe times and that organizations are still doing far too little to improve safety. In addition to that, companies do not always help to improve the public's perception of safety because their safety performance is by no means at the desired level of zero accidents. Yet the idealistic strive for zero accidents is an ethically justified objective for safety that even our $19^{\text {th }}$ century time traveller would relate to. 
Not just the level of safety but also the nature of today's safety discussion has broadened. For example, children playgrounds safety would seem strange, even laughable, to our time traveller. Their child-safety concern was much closer related to children crawling on their knees in coal mines, or children changing spools of yarn in unprotected spinning machines in textile mills.

Under the influence of safety innovations, optimisations and implementations the safety terminology changed completely since 1900s. One of the intellectual crown jewels of the modern approach to safety, is thinking in terms of risks. The introduction of the concept of risk has opened up a multitude of possibilities for improvement that simply did not exist before. Risks can now be mapped and measured with QRA techniques of which Bayesian Networks are examples but there are many, many more (Lees, 1996; Cooke, 2009; Pasman, 2015). Inventive prevention measures can be devised, assessed, tested and implemented so that risks can be controlled and accidents prevented. To this end, various instruments, and metaphors were developed and optimised: e.g. Risk Inventory and Evaluation, Task Risk Analyses, Last Minute Risk Assessments, and Bowties, to name just a few.

It may be clear, even to our time traveller that prevention is more important, and more efficient, than cure. But only in the last decades of the last century innovative theories, management systems and technical provisions been devised, optimised and implemented to put this wisdom into practice. Prevention and source control have now been given preference over all other measures and the broad choice in solutions would overwhelming to our time traveller. Fortunately, he or she is helped by innovative graphical representations that facilitate the understanding of different approaches. This includes approaches that vary from Swiss Cheese, Bowties, Drift to Danger, triangles and icebergs to dominoes and ladders (Swuste et.al., 2019d). Methods like 'Inherently Safe Design', and 'Layers of Protection', and various safety indexes have been developed to support effective implementation of safety (Kletz, 1985; Khan and Amyotte, 2002; Sugiyama et.al., 2008; Srinivasan and Natarajan, 2012). Safety experts of today learn the approaches and methods and their utility in special trainings occurring at all levels. In contrast to 1900 s, there is a wealth of transferable and immediately applicable knowledge. It is a major achievement that safety and control measures are now being investigated and taught even at an academic level (see for instance Swuste and Sillem, 2017). Our time traveller would notice that people from very different disciplines collaborate on safety. Nobody today is surprised when psychologists, sociologists, political scientists, safety experts, physicians and mathematicians are coming together to investigate, for example the role of fatigue in the functioning of humans in complex decision-making tasks, or in managing the complexity of modern production. To our time traveller, who might have worked in a safety team consisting of a manager, a safety engineer and a handfull of workers, it would be completely alien. Safety is no longer the exclusive domain of only the technician in industry, it is a melting-pot of expertise and experts. 
Our time traveller would notice remarkable improvements in all industries; a larger and wider understanding of factors contributing to safety presently; and widespread implementation of safety measures. But he or she would also recognize the growing complexity of technology and organisations and the need to further develop of safety science. Continuous improvement and optimisation remains as essential as it was over a century ago and stagnation of safety performance must be prevented at all costs. This mantra can be heard in academic circles but it mostly reverberates around all industries. Some scientists propose the complete overhaul of safety thinking. According to these scientists, traditional ways of thinking no longer lead to the further improvements. They dislike the accident related focus of safety and prefer to look at what goes well rather than what goes wrong. To the authors of this paper, and perhaps our time traveller, such a call for change is positive, being an incentive to develop new innovations for safety. It could actually serves as a wakeup call to reconsider the way safety processionals communicate about their initiatives. As with any innovation, there are some reservations in the sense that progress should not lead to the misunderstanding of what has already been achieved and to rejecting the achievements of knowledge and tools developed in the past.

\subsection{Science and practice}

Scientists think in terms of causes, while practitioners think in terms of remedies. Scientists think critically and ask fundamental questions about the structure and content of models and the efficiency of resulting interventions. An inherent problem with the scientific approach is that it appears to be difficult in to devise unambiguous experiments to determine whether safety programmes, interventions, concepts or optimisations actually work. A purely scientific approach, using randomised controlled trials as a research design, makes modelling and quantifying the active ingredients of an intervention with 'real people' in 'real organizations' in an open organization almost impossible. This research design, enabling to address various forms of bias, runs up against a number of insurmountable practical and ethical problems in safety science research while studying effects of interventions (Molen et al., 2007). If we take the example of 'Life Saving Rules' as a set of simple rules to limit consequences of an incident (such as requiring wearing fall protection when working at heights) it is hard to test scientifically what exactly the contribution to the safety-record is. But from a practical point of view, however, life-saving rules offer simple and clear guidelines for safe behaviour that can be implemented and supported throughout. This dichotomy makes it difficult to publish articles on change processes in organizations in scientific journals. As a result, there appears to be a division between the real and the scientific world. Real world knowledge is mainly described in handbooks and contains face valid models, supported by hard to verify, but appealing case studies. The scientific approach tends to be reported in dedicated journals that require application of scientific methods on relatively narrow aspects of safety. This scientific approach rarely produces inspiring stories and only sporadically produces readily applicable instruments. At the end of scientific 
publications, limitations and shortcomings of the study are listed and assessed but scientists often do not take the trouble to translate scientific insights into practical information that the expert in the field can apply. For many practical safety experts scientific insights are almost irrelevant (Srinivasan and Natarajan, 2012; Reiman and Viitanen, 2019; Shorrock, 2019; Swuste et.al., 2019e).

\section{THE FUTURE OF SAFETY SCIENCE}

\subsection{Questions for the future}

In 1962 the British science fiction writer Arthur C. Clarke formulated his third law: 'Any sufficiently advanced technology is indistinguishable from magic'. (Clarke, 1962). Seeing the present state of safety in modern countries, our time traveller could not have given a bigger compliment to all those parties who have worked on improving safety in recent decades. The sorcery of safety science has saved the lives of hundreds of thousands of people in the last century and prevented the suffering of millions. Strengthened by this success, safety experts and risk professionals must continue along this path together, so that the time traveller, journeying on to the future, would see that much more could still be done. Future generations of safety scientists will be required on the continuous strive for improvement and no doubt safety will experience several leaps forward.

One of the important decisions that history will have to make is whether there is a need for completely new ways of academic thinking, or that existing knowledge provides sufficient scientific grounds for future safety improvements? Can we make a hospital just as safe by using knowledge of safety methods in refineries, or of aviation? Do small businesses require fundamentally different tools as safe as larger ones? And if a new way of thinking is required how can we develop a practical set of instruments and an understandable conceptual framework so they make sense in a working organization? How do we deal with future risks? Does the increasing introduction of robots in the workplace and the growing role of artificial intelligence in increasingly complex processes challenge safety or does it lead to new risks, for which the current instruments may be insufficient. Scientists have an important role to play in this thought process but will they be able to create sufficient practical handles to benefit industry?

When our time traveller travels around the world, and further in time he, or she would recognise 'black countries', referring to heavily industrialised areas. A few late $19^{\text {th }}$ century artists painted these landscapes. Industrial pollution, which had blackened these areas, also generated local climate changes. These were discussed by the upcoming public and occupational health movements of that time. Our time traveller would recognise these landscapes today in developing countries and in major economic powers, like China. But our time traveller would be surprised to find climate change, and extreme weather conditions, not being a local problem, but increasingly a worldwide one, being 
discussed in science, politics and the public media for decades already. While causes of this phenomenon are not very different from those creating the 'black countries'. Climate change will initiate a mechanism, called 'societal drift' by sociologists. Drift is a mechanism relating to Rasmussens' drift to danger model (Rasmussen, 1997), and will influence what is culturally defined as tolerable risk. It also will effect public debates on hazards. Eventually it can have an impact on the existence of societies and countries and becomes an existential risk (Pettersen and Fjæran, 2019; Le Coze, 2019).

Our time traveller, being familiar with the mechanisation of the textile industries would frown his eyebrows when literature is discussing 'Industry 4.0'. After the introduction of electricity, making machines faster, and more powerful, the assembly lines, electronic, and automation. Industry 4.0 is a recurring theme in contemporary literature in Western countries (Badri et.al., 2018). This fourth generation of digital manufacturing would use real-time wireless communication, amongst other things being able to detect hazards and dangers effectively. Big data-analysis will also be used to manage the vast amounts of data generated by production, as well as by remote sensing, and even contribute to the development of safety-conscious robots, which will recognize injury inducing actions (Gulijk et.al., 2015, 2018; Figueres-Esteban et.al., 2018). However, major challenges remain.

\subsection{Old problems, new jacket}

The main challenge of safety science is, and remains, to understand accident processes, both occupational and in high-tech-high-hazard sectors. Knowing the accident process is a solid starting point for developing effective interventions. Future industries, and particular in high-hazard-high-risk sectors will keep on reducing staff levels, use smaller facilities and installations, encourage the use of compact and robust technology. The workers and operators that are still there will need to acquire a wide range of quite specific safety skills as they did in the past. The only real novelty is the introduction of computer skills in combination with conventional safety-associated expertise. The hightech-high-hazard sectors would still depend on so-called safety-critical systems and system assurance. These steadily more advanced systems and computers are 'embedded' in society, and will create new failure modes but the overall aim to prevent accidents will remain. Damage, caused by failures of advanced loT systems and computers would not be caused by physical effects alone, like for instance explosions, but also by removal of service, or damaged, or inadequate information (Knight, 2002) which widens the span of risks but not it's consequences. Also, areas of research, like ergonomics and human factors, which will remain and perhaps increase their increase importance when the world becomes more digitized. The attention could shift towards focussing on control interfaces, and man-machine interactions (Bari et.al., 2018). As before, some sectors would fall behind in these developments, such as small and medium sized enterprises. For these sectors it is 
not only the increased complexity of future production processes, but also the increasingly complicated set of laws and regulations, which become ever more difficult to understand and to manage for this group of companies. And, as in the past, there is hope for such organizations: the European strategy for producing future chemicals there is a tendency to 'do less and better' when it comes to regulations (Roger, 2003). And as before, there are no clear indications that industries that tended to be slow in following-up on safety innovations, such as the construction industry or the textile industry, will surpass other industries in safety performance. Due to the nature of the work their incident occurrence has consistently been relatively high there is no reason to assume that this will change any time soon.

\subsection{Examples of high-tech-high-hazard sector, language, safety-aversion, and design}

In the coming decades, construction is also becoming more of a high-tech-sector, judging from the many impressive buildings and structures this industry now, and in the future produces. But in many countries construction also remains a high-risk sector, and most likely it will keep this position for decades to come. Accident statistics in construction are amongst the highest and the type of accidents has barely changed in the last 50 years. Apart from the high-tech aspects in this sector, construction employs relatively large numbers of low education workers, performing manual labour. In many countries this low literacy group of workers is foreign, and unable to speak the local language. Language ignorance can thus become a hazard. Any written communication, including safety related topics, are usually produced by people with a high level of education, but a majority of such workers would not be able to understand these written messages. Furthermore, most likely these language barriers are also cultural barriers too (Lindhout et.al., 2012; Swuste and Jongen, 2013). One of the characteristics of this sector is its so-called organic structure: there is a low level of standardized work performance, and building sites would change now and then to different locations. Different from most factories, in the construction industry the mother company is located elsewhere. Consequently loyalty of construction workers will usually be more focused on fellow workers than on the mother company, contributing to a culture of aversion to rules, and procedures. Decision-making on planning and execution, including safety, is, in practice, largely conducted at a low level in the organization. Because of many laws, and regulations, safety in this sector is primarily focused on compliance, and safety is seen as a bureaucratic burden. Projects in this sector always involve many parties, and therefore legal responsibilities in case of accidents becomes rather uncertain. Generally parties lower in the construction hierarchy are saddled with the consequences of accidents. Safety is restricted to programs promoting safety conscious behaviour of workers, without paying much attention to possible accident processes, and accident scenarios. This approach inevitably leads to safety-aversion behaviour of workers and managers. Additionally the separation between design and construction is very rigid. Architects are generally insufficient aware of possible hazards for workers (Swuste et.al., 
2012). Factors like safety aversion and the danger enhancing gap between design and construction would probably sound familiar to our time traveller.

Two other high-tech-high-hazard sectors, the process industries and the oil sector, design is a major issue in designing out accidents. It has been for some decades and it is likely to be so for decades to come. The accident processes that occur in these industries are complex, and difficult to reproduce or predict. Some researchers worry that the potential damaging effects of large masses of (intermediate) products, and process fluids are still largely underestimated (Radamaeker et.al., 2014). As in construction, cost reduction, and time pressure are important drivers in these sectors, and major accidents could repeat themselves around the world before decisive action is taken. A lack of knowledge by management, which is often too busy with every day's operational issues and often also lacks an overview of possible accident scenarios, remains a major attributing factors of these major accidents. In the coming decades, process industry will change from being largely based on petroleum to being based on other energy carriers, such as natural gas, and hydrogen $\left(\mathrm{H}_{2}\right)$. Hazards of large based storage of these new carriers, and distribution, hydrogen in particular, requires careful design, construction, planning, and maintenance (Pasman, 2015). The technical design of safe systems will remain a major issue. For a long time, risk management was performed only after detailed design of a new plant has been completed, which is too late. Controlling the emission of a hazard, before a hazard becomes out of control is far more effective than add on measures dealing with exposures to hazards. This is the basic message behind Inherent Safe Design. But like construction, the loop from operational experience back to design has not been closed sufficiently. While there is a large body of research on inherent safety assessment methods, little is said on best ways to incorporate these methods into the work processes of practicing engineers (Khan and Amyotte, 2002; Srinivasan and Natarajan, 2012; Radamaeker et.al., 2014). There is no reason to believe that these methods could not be optimised and implemented in the future and will become operational in the coming decade.

Our time traveller would be surprised to see that phenomena in bio- and nanotechnologies could result in so many new processes and products. Especially nanotechnology has received much attention the last decades, both in scientific, and in popular literature, and also in the media. Applications of this new technology seems endless. While nanomaterials in toothpaste, sun cream, tiles, glass, and many other products are already on the market, a large number of new medical, industrial and consumer uses are expected in the next decades. The big advantage of these materials follows from their extremely small particle size: $1-100$ nanometers $\left(1 \mathrm{~nm}=10^{-9} \mathrm{~m}\right)$, which is a (sub)molecular scale and change the properties of the materials. But in the introduction of those new properties lie safety risks. Particles in the nanometer range exhibit properties, such as quantum effects, which are significantly different from those at larger size scale. For example, nanomaterials 
are extremely reactive, compared to bulk versions of the same materials. This reactivity is somewhat frightening for some scholars, even suggesting a similarity to asbestos, especially nanotubes, because of their resemblance with asbestos fibres, being once called the 'magic mineral'. Exposure to workers and to the public is the issue here, making nanomaterials an issue in occupational and environmental hygiene, and toxicology. But there is definitely a safety aspect too. Most likely nanotechnology would develop further, while process, safety, and hygiene knowledge would lag behind. Inherent safe design seems a sensible approach to reduce or eliminate workers' exposure, since exposure follows emission. Controlling emission will thus automatically control exposure (Srinivasan and Natarajan, 2012; Silva et.al., 2015, 2016).

\subsection{Knowledge, linear models, quantification, tracing scenario developments}

Perhaps to our time traveller's surprise, for some consecutive decades, safety scientists are convinced that accident processes are becoming increasingly complex without a clear definition of what complexity means in a safety context. Also the increasing complexity of production in high-techhigh-hazard sectors is acknowledged. Some scientists propose that contemporary scientific literature is awash with linear, sequential models of accident causality, and so-called epidemiological models that are insufficient to deal with these complexities. This group of scientists proposes that these models are reactive and primarily focussing on 'learning from events' where memory is a prerequisite for learning, but organisations, and companies do not have a memory of their own, unless it is organised (Rademaeker et.al., 2014; Shire, et.al., 2018). Familiar culprits of linear sequential thinking are found in Fault Tree Analysis, Root Cause Analysis, Human Performance Enhancement System, the Swiss Cheese metaphor, Tripod, Management Oversight Risk Tree (MORT), and the Bowtie metaphor. The literature presents various dynamic models, like the Dynamic Sequential Accident Models (DSAM) and Dynamic Risk Assessments (DRA). DSAM are sequential models with a systematic procedure using precursor data estimating the posterior risk profile quantitatively (AIshanini et.al., 2014). The second example, DRA, is a risk assessment updating estimations of risks of a failing system, using states of its components in time. DRA can capture time-dependent behaviour of system risk profiles (Zio, 2018).

These dynamic models are quantified approaches to accident processes. Quantification is particularly favoured by risk analysts. But many risk models contain little information on accident processes. This statement is also true for various safety indexes, used in process industries, like Dow Indices- Dow Fire \& Explosion Index, Chemical Exposure Index, Hazardous Chemical Index, Hazardous Reaction Index, Total Chemical Index, Worst Chemical Index and Worst Reaction Index. Apart from their quantification, these indexes have various shortcomings. The categorization used is quite subjective, e.g. the weighting of hazards. In addition, coverage of phenomena quantified with an index is generally limited (Sugiyama et al., 2008; Srinivasan and Natarajan, 2012). A similar approach to 
indexes is that of safety performance indicators, which have already been developed for some decades ago (Swuste et.al., 2016b; Zio, 2018). Also here, quantification prevails. Although quantification in itself can have its merits, there is also a downside in reducing reality to a number. Quantification generates questions on the meaning and interpretation of the numbers. A combination with qualitative approaches is therefore necessary to come to an adequate view and appraisal.

Recently, process safety indicators, both technical and managerial, have been closely linked to current accident theories, models and metaphors, connecting them to our present understanding of complex accident processes. When applying such approach to a specific sector, an overview from literature, interviews with workers, and managers, and company documentation should provide all possible major accident scenarios of the sector. Because the number of scenarios can easily exceed a manageable number, a reduction considering only the most credible scenarios is necessary, guided by assumed probabilities of occurrence, and seriousness of possible adverse effects. Linking these indicators with process control alarms in a process industry allows management and workers to have a unique insight in a time-dependent developments of scenarios, and consequently their prevention (Nunen et.al., 2018; Schmitz et.al., 2019; Swuste et.al., 2019d). Middle, and top managers, including safety staff do not have time to generate such an overview. Other time consuming activities, like law compliance, facing external threats, or internal problems related to production, or organisation would always compete.

\subsection{Impact of non-linear models, safety theory and practice}

Other, so-called qualitative systemic models are, for instance Rasmussens' Accimap model (Svedung and Rasmussen, 2000), System-Theoretic Accident Model and Processes (STAMP) (Leveson, 2004), and the cognitive system models of Functional Resonance Accident Model (FRAM) and Cognitive Reliability and error Analysis Method (CREAM) (Hollnagel, 1998). Accimap refers to control theoretical concepts with organisational, managerial, and operational frameworks as preconditions for accidents. STAMP is based on system theory and represents accidents in non-linear complex systems. A lack of control, originating from external disturbances, or system component interaction is the precondition for accidents. CREAM starts from cognitive characteristics of human performance to understand human error consequences, and FRAM starts from stable internal, external and performance variabilities in systems under study (Al-shanini et.al., 2014; Shire et.al., 2015). Our time traveller would be surprised that although these new models have been around for years their impact on the way safety is managed in most organisations is very limited. The translation of these systemic models into practical applicable tools have proved to be remarkably difficult. The time traveller might wonder why the academics involved in developing these systemic models have not worked closer with professionals to develop such tools. The contrast in speed in which technological improvements are adopted by the industry compared to these new ways of thinking is striking. 
A very different qualitative approach, dealing with complexity, is the High Reliability Organization Theory from the late 1980s. High Reliability Organisations (HRO) are organizations with complex processes, but where relatively few accidents occur. It is a label for extremely reliable organizations carrying out dangerous activities. This approach is at odds with the current management approach which focusses on mechanistic efficiency, ensuring that operators, who simply do not have time to solve problems, to work according to procedures. This current approach is thus not just about time as a limiting factor, but also about human operators, who according to $\mathrm{HRO}$, can no longer manage present day complexity and variability of processes. Feedback control, which is a logical route of management from system theory, corrects the current state of a process to a desired state. In dynamic processes of HROs, the desired state is a kind of utopia and the concept of feedback no longer works. Overall there are two options: either systems must be made less complex, the Inherently Safe message from Kletz, or the operator, in fact the organisation, must become smarter. If the problem is that a process exhibits complexity and variety too large for a single individual employee, then the solution is addressing problems in networks or in teams, which are diverse in terms of knowledge and disciplines. Diversity provides a better guarantee for reliability than a team with a homogeneous composition. (Weick, 1987; Roberts, 1988). High Reliability Theory, and Resilience Engineering, two approaches to complexity, which have much in common, would most likely dominate academic discussions in the forthcoming decades (Hale and Heijer, 2006; Patriarca et.al., 2018). Transforming these concepts for safety professionals is still a difficult issue. These paragraphs above illustrate the large variety of on theories, models and metaphors currently existing.

Knowledge development needs credible international organizations to promote improvements in management systems, in safety technology, and, further, the means to disseminate this information through publications and conferences. For the process industries, the 1984 Bhopal disaster was a wake-up call in the United States, and the creation of the Centre for Chemical Process safety (CCPS) by the American Institute of Chemical Engineers (AIChE). The Centre stresses the primacy of Inherent Safe Design, rather than focussing on procedures and add-on measures. The Centre also underlines the importance of awareness of the total cost of major accidents, as well as a consideration of the broader societal and cultural aspects of major accidents. The need for competency in process safety theory and practice is not restricted to plant operators and system designers; managers and corporate leaders must also understand the risks intrinsic to the work they direct. In addition to the CCPS other centres with similar goals have been created, like the US Mary Kay O'Connor Process Safety Centre, Texas A\&M University (1995) and Doha, Qatar (2013), the US Chemical Safety Board (1998), the Canadian Society for Chemical Engineering (2012), the UK Health and Safety Executive (1974), and the Working Party on Loss Prevention under the umbrella of the European Federation of Chemical Engineering (1974) (Pasman and Sutter, 2005, Amyotte et.al., 
2016 ). And universities are main centres for knowledge development. Nevertheless a number of previous active groups, like the Loss Prevention Group of the Chemical Engineering Department of the Delft University of Technology no longer exists (Lemkowitz et.al., 2000). Also other process safety groups in Europe have disappeared the last decades, and education is largely restricted to professional training, or to polytechnical schools.

\subsection{Education}

A contributing factor to (major) accidents is lack of knowledge and insight into accident processes. If leaders of companies are not aware of hazards and risks, their organisations, of companies reach a stage of so-called 'wildness in the wait' (Pasman, 2015). This lack of knowledge, which was a very dominant factor in the $19^{\text {th }}$ century, is still present today although in a milder form. Safety, and particularly safety in high-tech-high-hazard sectors deserve separate attention. For leaders and top managers a training might be sufficient to create awareness acknowledge the importance of safety, and the risks in their business. Plant managers, and operators, and process and safety engineers will however need a more thorough insight into these topics. Partly vocational and polytechnic courses on occupational, and high-tech-high-hazard safety would be sufficient, in combination with environmental safety and health. But there is also a need for safety experts able to analyse and solve unexpected problems. A key factor here is the quality of the safety expert. Fast changing technology and aggressive market forces, which most likely will be active for decennia to come, require companies to employ safety experts trained at academic, or post-academic level. Here the emphasis is on learning by doing instead of learning facts, and on discussion as essential elements in learning (Dijk, 1995; Saari, 1995; Kletz, 2006). These experts would be trained to address new problems by applying knowledge and skills to situations not previously encountered. Problem solving, in contrast to rulefollowing, seems best trained at a (post)academic level (Chimote, 2010; Wybo and Van Wassenhove, 2016). In literature, discussions on the content of process safety, and process integration courses

have started already (Srinivasan Natarajan, 2012; Mkpat et.al., 2018) and on the quality requirements of (post) academic courses on safety (Wassenhoven et.al., 2019).

\subsection{Two non-western countries, Pakistan and China}

Two non-western countries will be discussed here; Pakistan and China. Pakistan is a country with a relative low level of industrialisation and a large informal sector, like many African and some South American and Asian countries. China is an example of a country coming from a lag in economic development to a strong industrial growth. Some South American and Asian countries followed a similar maturation. Of these two countries, our time traveller would be somewhat familiar with Pakistan. Here the informal sector of the economy is an employment refuge for most workers. Small enterprises and the informal sector form de facto the mainstream of economic activities. In Pakistan the percentage of employment in the various informal sectors is almost $75 \%$. The main informal 
sectors are wholesale \& retail, manufacturing, and construction. Industry is mainly focused in the eastern province of the Punjab, the most important province with the largest population. A lack of knowledge is a main concern, regarding safety and health. Hardly any safety facilities, like fire extinguishers, safety training, transportation to carry injured workers, social insurance, health examination and medical records of employees, are available. The level of education amongst those working in these sectors is low, with no education or less than 10 years of schooling. There is virtually no active labour inspection. Labour laws and regulations are inherited from the British Colonial area, and are outdated (Besserman and Mentzer, 2017). Hazards and risks in workplaces resembles $19^{\text {th }}$ century European conditions. There is a whole list of risks: excessive noise levels, exposures to hazardous chemicals, working at dangerous elevation, exposure to heat and cold, ergonomic hazards, poor lightening quality, high levels of vibration and low fresh air circulation. There is no clear picture on national accident statistics, due to the large size of the informal sector, but literature suggest that construction is the sector with the highest incidence on accidents, mainly caused by falling from heights. The most basic risk factor is poverty. But much of the history of public health, and occupational safety, health and hygiene can be viewed as their ability to successfully pinpoint specific subcategories of attributional risk in the form of nutrition, environment, working conditions, education and medical care. These risks can be reduced by better education, technology, and management to achieve improved health, even before people reach middle class wealth levels. Not to consider poverty alleviation as the primary means to improve safety and health is to ignore the huge potential improvements that can be achieved well before that far-off day when poverty is eliminated (Swuste and Eijkemans, 2002; Ahmed et.al., 2018).

The second country, China, is very different in many aspects. Unlike Pakistan, a British creation of the 20th century, China's history goes back thousands of years. Presently China is the second largest economic power in the world, a result of an extremely rapid industrialisation, mainly concentrated on the eastern and south-eastern provinces of the country: Shandong, Jiangsu, Sichuan, Shanghai, and Guangdong. This dramatic industrial expansion has, however, also a downside in a country with weak foundations of industrial safety and poor safety awareness. The five most hazardous sectors are 1/ coal mining, 2/ metal and non-metal mining, 3/ construction, 4/ chemical process industries, and 5/ fireworks. Since ca. 2005 preventing major accidents (between 10-30 fatalities, and damage between 7-14 $10^{6} €$ ), and serious ones (more than 100 fatalities, and damage more than $1410^{6} €$ ) have become a key government work priority. The State Administration of Work Safety became a separate organization and began reporting directly to the State Council of People Republic of China and to the State Administration of Coal Mine Safety. Also since ca. 2005 half of the operating coal mines, generally small but highly hazardous ones, were shut down, and the Chinese government have stimulated the certification of its safety professionals (Wang, 2019). In 2016 industrial safety again became a national priority with the $13^{\text {th }}$ Five-Year Plan, period (2016-2020). The plan consists of a 
strict supervision, thorough investigation of major and serious accidents, and launching a nationwide safety campaign. Judging from official statistics this rigorous control approach seems to work. With almost 80 major and serious accidents every year between 2002-2005, killing yearly almost 2000 workers, these absolute figures dropped to around 20 major and serious accidents with a yearly mortality of 370 (Wang et.al., 2018a). This result is rather spectacular, although relative figures, including the number of facilities would present a more realistic picture than absolute figures. Recently much emphasis is given to safety laws, and regulations, avoiding inconsistencies, integrating rules, and standards, and improving inspections. Literature, however, shows that prevention and limiting consequences of major and serious accidents in China are still quite problematic and some challenges exist. (Wang et.al., 2018b).

\section{DISCUSSION AND CONCLUSIONS}

This contribution is written from a position of a third person, the time traveller from the $19^{\text {th }}$ century, who is very surprised, even sometimes astonished, but now and then familiar with the present day events, and future developments in safety and safety science. In occupational safety, progress has been incremental. This changes dramatically from the 1970s onwards, when safety becomes the academic discipline of safety science, and the world has been shocked by major accidents in hightech-high-hazard sectors. Most of these major industrial accidents have also occurred in Western countries, and in companies with a good safety reputation (Hale, 2002). There has been no indication in the past, nor is there any reason to believe that this will change in the future: safety, at least in part, is driven by major accidents

Although risks can be evaluated at all stages of an industrial system life cycle, hazard identification and risk reduction are always more efficient and more cost-reducing when incorporated into the earliest design stage of an industrial project (Badri et.al., 2018). As systems are becoming more complex, anticipating on all failure pathways is virtually impossible. There are also limits to design options. The complexity of processes make it almost impossible to foresee all safety related conflicts. Emphasis is shifting to assuring the presence of capacity to handle unforeseen events, rather than assuring the absence of failure modes through design (Rasmussen, 1997). Complexity in technology is mainly restricted to new, and experimental technologies. Here, many unexpected interactions may occur as a starting point for an accident process. In these cases dynamic models and methods can show their value. In well-understood technologies, already part of production for many decades, sequential models and metaphors are sufficient. The complexity and non-linearity of accidents will remain a research issue; this is supported by dynamic modeling and IT systems of the future. 
Complexity is a concept that is not only applicable for production processes. Similarly, laws, and regulations can be complicated, as shown in the case of medium and small enterprises, or in the examples of Pakistan and China. Another type of complexity is related to decision making. There is an increase in participation of special interest groups, like trade unions, environmental activists, community groups, scientists, showing their social involvement and their demand for protection. Public participation, and resultant public interference, are increasing. There appears to be a serious danger of a 'Hydra effect', every solved risk problem generates two other problems (Covello Mumpower, 1985). The second law of thermodynamics states that the entropy of an isolated system can never decrease over time. To some extent, improving safety in a complex system can be seen as a fight to reduce entropy. Ultimately, the amount of energy needed to eliminate the last bit of entropy would exceed the capabilities of society. In other words: to achieve the level of control over a system to prevent the last accident might cost so much that our society cannot bear the costs. The fight against 'lone wolves' to prevent terrorist attacks is an example where the total costs to identify these individuals is close to exceeding what our (Western) society can bear and finds acceptable. Do we have to cut all trees in a country to prevent a few driver fatalities? Do we need a dystopian control system to monitor all movements, states of our body and even thoughts to prevent even the slightest possibility of an injury or would that just remain a frightening scene from a black mirror episode? Would our time traveller in the future see an uprising where people demand more freedom, e.g. to climb trees again and take the risk of a broken ankle for granted? The question of course is 'when is enough, enough', what is an acceptable amount of accidents given the societal costs to prevent them? This is a political question than one that can be answered by safety professionals. However we're not even close to reach that stage, but ultimately our time traveller would notice that the second law of thermodynamics would roar its ugly head. The drift to danger i.e. the balance between cost and safety gain will remain even if innovations drive towards new optima for fewer accidents.

This contribution shows some challenges for the coming decades. Starting with future developments in industry, a major challenge is man-machine interactions described in Industry 4.0. Another issue, cited a few times in this contribution, is the translation of research findings for professionals in practice. This would, for instance benefit the construction sector. A major reduction in accidents would be possible if responsibilities for safety becomes clear in this sector, and construction designers show an interest in the actual reality of construction sites, and/or construction workers being involved in the design process. There are, obviously some direct problems here. Apart from time, designers are often overwhelmed by addressing all sorts of regulations regarding safety. Suppose all these safety related laws, rules, and regulations are simplified, and integrated. Or, even more extreme, we get rid of all these rules and regulations, and start addressing safety from a viewpoint of possible, or actual accident processes. In more sectors these rules and regulations are seen as a nuisance, creating a situation where safety is regarded as cumbersome, and as a bureaucratic activity. There is always the 
danger that improvements that these rules and regulations once bought are all but forgotten, a situation not unlike the decline of the level of vaccinations against diseases that were once ravaging societies. It is the role of future safety professionals to remember the past and communicate about the 'why' of certain safety measures that to the future citizens of the world might look more as a nuisance than a life-saving measure.

One more challenge refers to safety as a science. Nowadays occupational, high-tech-high-hazard, public and environmental safety are regarded as separate domains. Neither amongst scientists, nor amongst practitioners are there yet signs of integration yet of these domains, while for the general public borders between these disciplines are difficult to understand. Another challenge is safety education. An infrastructure in some countries to generate, and to disseminate present, and new knowledge already exists for some decades now. Their challenge is to get top managers on board, and to increase the importance of safety issues in board room decision-making. The shift from safety through design, and compliance with rules and regulations, towards assuring presence of capacity to handle unforeseen events requires board room involvement. Education may also play a role in the integration of the various safety domains, mentioned above. However the absence in some countries of separate (post)academic courses on process safety and process integration is worrying.

A completely different point is the status of safety science. Many concepts in the safety domain are borrowed from other sciences, and are applied to safety-related topics and problems. Safety professionals and academics use terms like 'failsafe', 'safety culture', 'safety barriers', 'latent factors', 'system redundancy', 'risks', 'resilience', etc. But the concept of culture comes from anthropological sciences, latent factors from sociology, resilience from social sciences, and risk from mathematics. These origins are so disparate that their links are hard to define. Safety science applies concepts from other disciplines but can't quite make them their own. Some other safety concepts are largely the result of common sense. Safety science has only just begun to add proven theories to those building blocks of existing science and common sense. Scientific domains often start as multi-disciplinary . Regarding the multitude of theories, models, and metaphors, coming from various scientific domains, safety science is definitely multi-disciplinary. Generally, however, scientific domains evolve from a multi-disciplinary status to an inter-disciplinary status, characterised by an agreed paradigm, which till now is mostly absent in safety science. Eventually scientific domains tend to reach a monodisciplinary status and safety science is no-where near that. So there is still a long way ahead for safety science. At present the safety domain is vulnerable, and may disappear as a separate scientific domain, and be absorbed by, for instance, policy sciences, law, or engineering sciences. But in the eyes of our time traveller, the efforts over the last 150 years have been very worthwhile and have proved fertile grounds to improve even further, even if that mostly means carrying on as before. 


\section{REFERENCES}

Ahmed I Usman A Sajid M Zeeshan M (2018). Safety practices in informal industrial segment of Pakistan. Safety Science 110: 83-91

Al-shanini A Ahmad A Khan F (2014). Accident modelling and analysis in process industries. Journal of Loss Prevention in Chemical Industries 32:319-343

Amyotte P Berger S Edwards D Gupta J Hendershot D Khan F Mannan M Wouldey R (2016). Why major accidents are still occurring. Current Opinion in Chemical Engineering 14:1-8

Badri A Boudreau-Trudel B Souissi A (2018). Occupational health and safety in the industry 4.0 era: A cause for major concern? Safety Science 109:403-411

Besserman J Mentzer R (2017). Review of global process safety regulations: United States, European Union, United Kingdom, China, and India. Journal of Loss Prevention in the Process Industries 50:165-183

Chemical Industries Association (2008). Process Safety leadership in chemical industries CIA London

Chimote N (2010). Training programs Evaluation of trainees' expectations and experience. The IUP Journal of Organisational Behavior 9(3):28-47

Clarke A (1962). Profiles of the future. Victor Gollancz Ltd

Cooke R (2009). A brief history of Quantitative Risk Assessment. Resources https://www.resourcesmag.org/archives/a-brief-history-of-quantitative-risk-assessment/

Covello V Mumpower J (1985). Risk analysis and risk management: an historical perspective. Risk Analysis 5(2):103-120

Dickens C (1854). Hard Times. Reissued as Penguin Classic 1993

Dijk F van (1995). From input to outcome: changes in OSH education and training. Safety Science 20:165-171

Figueres-Esteban M Hughes P El Rashidy M Gulijk C van (2018). Manifestation of ontologies in graph databases for big data risk analysis. In Haugen et al. (Eds.). Safety and Reliability, safe societies in a changing world. Taylor \& Francis Group, London

Gulijk C van Figueres-Esteban M Hughes P (2015). Big Data Risk Assessment the 21st Century approach to safety science. In: International Railway Safety Council 2014, 4th 9th October, Johannesburg

Gulijk C van Hughes P Figueres-Esteban M El-Rashidy R Bearfield G (2018). The case for IT transformation and big data for safety risk management on the GB railways. Journal of Risk and Reliability 232(2):151163

Hale A Heijer T (2006). Defining resilience. In: Hollnagel E Woods D Leveson N (Eds.), Resilience Engineering: Concepts and Precepts. Ashgate Publishing Ltd

Hale A (2002). Conditions of occurence of major and minor accidents. Tijdschrift voor toegepaste Arbowetenschap 15(3):34-41

Hollnagel E (1998). Cream-Cognitive Reliability and Error Analysis Method. Elsevier Science Ltd, Oxford.

Khan F Amyotte P (2002). Inherent safety in offshore oil and gas activities: a review of the present status and future developments. Journal of Loss Prevention in Chemical Industries 15:279-289

Klein J (2009). Two centuries of process safety at DuPont. Process Safety Progress 28(2):114-122

Kletz T (1985). Inherently safer plants. Plant/Operation Progress 4(3):164-167

Kletz T (2006). Training by discussion. Education for Chemical Engineers 1:55-59

Knight $J$ (2002). Safety critical systems. Proceeding of the Conference of the Journal of Computing Science and Engineering May 19-25 p. 547-550

Lateiner A Heinrich H (1969). Management and controlling employee behaviour. Enterprise Press NY

Le Coze J (2019). Visualising safety. In: Le Coze J (Ed.) (2019). Safety Science Research. CRC Press, Taylor and Francis Group, Boca Raton

Lees $F$ (1996). Loss prevention in the process industry. Hazard Identification, assessment and control. Butterworth Heinemann, Oxford

Lemkowitz S Pasman H Schupp B (2000). Integration of safety, health, environment and sustainability into engineering education and industrial training. Article presented at the 14th International Congress of Chemical and Process Engineering, CHISA 2000, 27-31 August, Prague, Czech Republic

Leveson N (2004). A new accident model for engineering safer systems. Safety Science 42(4):237-270

Lindhout P Swuste P Teunissen T Ale B (2012). Safety in multilingual work settings. Reviewing a neglected subject in European Union policymaking. European Journal of Language Policy 4(2):137-169

Mkpat E Reniers G Cozzani V (2018). Process safety education: A literature review. Journal of Loss Prevention $54: 17-27$

Molen H van der Lehtola M Lappalainen J Hoonakker P Hsiao H Haslam R Hale A Verbeek J (2007). Interventions for preventing injuries in the construction industry (Review). TheCochrane Library, Issue 4

Nunen K van Swuste P Reniers G Paltrinieri N Aneziris O Ponnet K (2018). Improving pallet mover safety in the manufacturing industry. A bowtie analysis of accident scenarios. Materials 11(1955)1-19 
Oostendorp Y Lemkowitz S Zwaard W Gulijk C van Swuste P (2016). Introduction of the concept of risk in the Netherlands. Safety Science 86:205-219

Pasman H (2015) Risk Analysis and control for industrial processes - Gas, oil and chemicals. A system perspective for assessing and avoiding low-probability, high-consequence events. IChemE, Elsevier, Amsterdam

Pasman H Sutter G (2005). EFCE working party on loss prevention and safety promotion in the process industries. Process Safety and Environmental Protection 83(B1):18-21

Patriarca R Bergström J Di Gravio G Costantino F (2018). Resilience engineering: Current status of the research and future challenges. Safety Science 102:79-100

PettersenK Fjæran L (2019). Drift and the social attenuation of risk. In: Le Coze J (Ed.) (2019). Safety Science Research. CRC Press, Taylor and Francis Group, Boca Raton

Radamaeker E Suter G Pasman H Fabiano B (2014). Review of past, present and future of the European loss prevention and safety promotion in process industries. Process Safety and Environmental Protection 92:280-291

Rasmussen J (1997). Risk management in a dynamic society: a modelling problem. Safety Science 27(23): $183-213$

Reiman T Viitanen K (2019). Towards actionable safety science. In: Le Coze J (Ed.) (2019). Safety Science Research. CRC Press, Taylor and Francis Group, Boca Raton

Roberts K (1988). Some characteristics of one type of high reliability organization. Organization Science $1(2): 160-176$

Rogers M (2003). The European Commission's White Paper 'Strategy for a future chemicals policy': a review. Risk Analysis, 23(2):381-388

Saari J (1995). Risk assessment and risk evaluation and the training of OHS professionals. Safety Science 20:183-189

Schmitz P Swuste P Reniers G Nunen K van (2019). Mechanical integrity of process installations - an analysis method with bow-ties and indicators. Chemical Engineering Transactions (to be published)

Shire M Jun G Robinson S (2018). The application of system dynamics modelling to system safety improvement: Present use and future potential. Safety Science 106:104-120

Shorrock S (2019). Safety research and safety practice: islands in a common sea. In: Le Coze J (Ed.) (2019). Safety Science Research. CRC Press, Taylor and Francis Group, Boca Raton

Silva F Arezes P Swuste P (2015). Risk assessment in a research lab during sol-gel synthesis of nano- $\mathrm{TiO}_{2}$. Safety Science 80:201-212

Sliva F Arezes P Swuste P (2016). Systemic design analysis and risk management on nanoparticles occupational exposure. Journal of Cleaner Production 112:3331-3341

Srinivasan R Natarajan S (2012). Developments in Inherent safety: a review of the progress during 2001-2011 and opportunities ahead. Process Safety and Environmental Protection 90:389-403

Sugiyama H Fischer U Hungerbuhler K (2008). Decision framework for chemical process design including different stages of environmental health and safety assessment. AIChE Journal 54(4):1037-1053

Svedung I Rasmussen J (2002). Graphic presentation of accident scenarios mapping system structure. Safety Science 44(5):397-417

Swuste P Eijkemans G (2002). Occupational safety, health and hygiene in the urban informal sector of SubSaharan Africa: an application of the Prevention and Control Exchange (PACE) program to the informalsector Workers in healthy City Projects. International Journal of Occupational and Environmental Health 8:113-118

Swuste P Frijters A Guldenmund F (2012). Is it possible to influence safety in the building sector? A literature review from 1980 until the present. Safety Science 50:1333-1343

Swuste P Groeneweg J Gulijk C van Zwaard W Lemkowitz S (2019a). Safety management systems from Three Mile Island to Piper Alpha, a review in English and Dutch literature for the period 1979 to 1988. Safety Science 107:224-244

Swuste P Gulijk C van Zwaard W (2010). Safety metaphors and theories a review of the occupational safety literature of the US UK and The Netherlands. Safety Science 48:1000-1018

Swuste P Gulijk C van Zwaard W Oostendorp Y (2014). Occupational safety theories, models, and metaphors in three decades after WO II, in the United States, Britain, and the Netherlands. Safety Science 62:16-27

Swuste P Gulijk C van Zwaard W Lemkowitz S Oostendorp Y Groeneweg J (2016a). Developments in the safety science domain, in the fields of general and safety management between 1970-1979, the year of the near disaster at Three Mile Island, a literature review. Safety Science 86:10-26

Swuste P Gulijk C van Groeneweg J Guldenmund F Zwaard W Lemkowitz S (2019b). Development of safety management between 1988 - 2010 (occupational safety). Review of Safety Literature in English and Dutch language scientific literature. Safety Science (in review) 
Swuste P Gulijk C van Groeneweg J Zwaard W Lemkowitz S (2019c). From Clapham Junction to Macondo, Deepwater Horizon: risk and safety management in high-tech-high-hazard sectors a review of English and Dutch literature: 1988-2010. Safety Science (in review)

Swuste P Jongen M (2013). Is taal een gevaar? Tijdschrift voor toegepaste Arbowetenschap 26(2):54-57

Swuste P Schmitz P Nunen K van Reniers G (2019d). Drawings, posters, photos, and metaphors in safety and safety science, some historical remarks. Springer Press (to be published)

Swuste P Sillem S (2017). The quality of the post academic course 'management of safety, health and environment (MoSHE) of Delft University of Technology. Safety Science 102:26-37

Swuste P Theunissen J Schmitz P Reniers G Blokland P (2016b). Process safety indicators. Journal of Loss Prevention in the Process Industries 40:162-173

Swuste P Zwaard W Groeneweg J Guldenmund F (2019e). Safety professionals in the Netherlands. Safety Science 114:79-88

Wang B Wu C Huang L Zhang Kang L Gao K (2018a). Prevention and control of major accidents (MAs) and particularly serious accidents (PSAs) in the industrial domain in China: Current status, recent efforts and future prospects. Process Safety and Environmental Protection 117:254-266

Wang B Wu C Kang L Reniers G Huang L (2018b). Work safety in China's Thirteenth Five-Year plan period (2016-2020): Current status, new challenges and future tasks. Safety Science 204:164-178

Wang B Wu C Li J Zhang L Huang L Kang L (2019). Certified safety Engineers (CSE) as a new official profession in China. A review. Safety Science 116:108-115

Wassenhove W van Swuste P Forteza-Oliver F Carretero-Gómez J Arezes P Kivistö-Rahnasto J Motet G Reyniers R Galera A Wenham D (2019). How to assess quality of graduate safety education? An example of nine (post)graduate courses in Europe. Safety Science (in review)

Weick K (1987). Organisational culture as a source of high reliability. California Management Review 29(2):112127

Wybo J Wassenhoven W van (2016). Preparing graduate students to be HSE professionals. Safety Science 81:25-34

Zwaard W (2007). Kroniek van de Nederlandse veiligheid. Van kinderarbeid en wassend water tot ontploffend vuurwerk. (Chronical of Dutch safety, from child labour and rising water till exploding fireworks) Syntax Media, Arnhem

Zio E (2018). The future of risk assessment. Reliability Engineering and System Safety 177:176-190 